\title{
Avaliação histológica do tecido conjuntivo ao redor de placas ortopédicas confeccionadas a partir de policloreto de vinila comercial (PVC) em cães
}

\author{
Histologic study of conjuntive tissue's reaction around bone plates made \\ from polyvinyl chloride (PVC) in dogs
}

\author{
Simone Rezende Galvão* Ricardo Junqueira Del Carlo* Marlene Isabel Vargas Viloria* \\ Luiz Gonzaga Pompermayer* Alfredo Maia Filho*
}

\begin{abstract}
Resumo
A reação do tecido conjuntivo ao redor de placas ortopédicas confeccionadas a partir de policloreto de vinila foi avaliada histologicamente em 30 cães adultos, com peso médio de $13 \mathrm{~kg}$, distribuídos em três grupos de 10 cães cada. Nos grupos 1 e 2 foram realizadas osteotomias transversais completas no corpo mandibular direito entre o último pré-molar e primeiro molar e as fraturas foram fixadas com placa de aço e de PVC, respectivamente. No grupo 3 , os corpos mandibulares íntegros direito e esquerdo receberam placas, sendo uma de aço e outra de PVC. Histologicamente, na $18^{\text {a }}$ semana, as placas de PVC desencadearam no tecido circundante uma resposta inflamatória crônica, qualitativamente diferente das placas de aço, afetando maior número de animais e em maior intensidade, sugestiva de toxicidade e antigenicidade do material.
\end{abstract}

Palavras-chave: policloreto de vinila; PVC; placas ortopédicas.

\section{Introdução}

Além da presença do implante influenciar no processo de recuperação do tecido traumatizado, a reação do tecido também pode produzir alterações superficiais no material implantado, degradando-o ou corroendo-o, atuando de novo no tecido receptor, e realimentando o processo inflamatório (Mariolani, 1991).

Aço, titânio, náilon, acrílicos, polivinilas e teflon têm sido empregados como substitutos de tecidos, alcançando resultados variáveis, pois sua implantação pode gerar reações dependentes da composição química do material, podendo levar à extrusão (Rubin et al., 1971). Segundo Marchant et al. (1984b), se o implante for muito grande para ser fagocitado ou rapidamente degradado, ocorrerá formação de tecido conjuntivo fibroso encapsulando-o. Esta seqüência de eventos é conhecida por reação de corpo estranho, que tende a isolá-lo do resto do tecido (Pereira, Bogliolo, 1993).

A intensidade e duração das reações no tecido receptor podem ser influenciadas pelo suprimento sangüíneo, liberação persistente de substâncias citotóxicas do implante, irritação física dos tecidos, sítio de implantação (Marchant et al.,1984b), infecção bacteriana (Marchant et al., 1984b; Smith, 1985), tamanho do material (Marchant et al., 1984a), composição química do material (Miller e Anderson, 1988), forma do implante e técnica cirúrgica (Morehead, Holt, 1994). Em implantes metálicos, íons podem ser causadores de reações teciduais (Uhthoff et al.,1981) e sua liberação pode ocorrer mesmo na ausência macroscópica de corrosão (Laing et al.,1967).

Reações teciduais a implantes variam em intensidade, desde franca toxicidade com rejeição e extrusão, para encapsulamento fibroso, e finalmente para integração com crescimento de células próprias do tecido na superfície do material (Morehead, Holt, 1994). Rubin et al. (1971) consideraram que o processo de extrusão do material estranho é modificado pela quantidade e qualidade do tecido de revestimento. Se a reação fluida é pequena ou moderada e o tecido de cobertura é abundante, haverá formação de uma cápsula fibrosa.

O PVC comercial é um polímero produzido a partir do cloreto de vinila acrescido de agentes emulsificantes, substâncias surfactantes, tampões, catalisadores e outros (Cook et al., 1971). Já o implante de material polimérico produz pequena reação inflamatória se o polímero for pouco tóxi$\mathrm{co}$, ocorrendo o seu encapsulamento por tecido fibroso (Hench, Ethridge, 1982), que inicialmente é composto por tecido de granulação, o qual é substituído gradativamente

\footnotetext{
* Departamento de Veterinária, Universidade Federal de Viçosa. 36570-000 - Viçosa, MG. E-mail: ricarlo@mail.ufv.br
} 
por matriz colágena (Davidson, 1992). Caso seja mais tóxico, a resposta inflamatória é intensa e a formação do tecido fibroso é retardada. Os produtos da degradação dos polímeros são mais tóxicos do que a maioria dos íons liberados por implantes metálicos (Hench, Ethridge, 1982).

Para Gebelein (1985), um implante com bordas arredondadas e superfície lisa origina pouca reação inflamatória, enquanto a movimentação do implante e a presença de plastificantes, estabilizantes e catalisadores a exacerbam. Segundo Wu et al. (1989), os estabilizantes e plastificantes acrescentados ao PVC podem migrar deste para o meio ao redor. Assim, em cirurgia reconstrutiva, é recomendado que apenas o polietileno puro seja utilizado, e que aditivos e materiais estranhos estejam ausentes (Counsell et al., 1985). O monômero cloreto de vinila tem provocado alterações ósseas e dermatológicas em trabalhadores das fábricas de PVC, sendo particularmente tóxico para o endotélio vascular (Magnavita et al., 1986).

Rodriguez Alvarez (1990) não observou alteração histológica nos tecidos ao redor do implante de PVC 30 dias após seu uso, como fixador interno èm cirurgia ortopédica. Já Tudury (1996), avaliando placas ósseas confeccionadas com este material, observou reação inflamatória granulomatosa e alterações vasculares no tecido fibroso que as envolvia, aos 45 dias após a sua implantação, com presença de plasmócitos, histiócitos e células gigantes multinucleadas, fagocitando o PVC. O possível caráter oncogênico atribuído ao PVC foi sugerido por Ward et al. (1976) e por Tudury (1996).

Marchant e Anderson (1986) observaram reação inflamatória aguda associada com intensa resposta inflamatória crônica com polimorfonucleares (PMN), após emprego de PVC acrescido de uma organotina, que, segundo Wu et al. (1989), é um aditivo tóxico, dos mais utilizados na confecção de tubos rígidos.

\section{Material e métodos}

Foram utilizados 30 cães adultos, sem raça definida, com idade de 2 a 4 anos, clinicamente sadios e com peso entre 10 e $16 \mathrm{~kg}$. Os animais foram distribuídos em três grupos de 10 cães (grupos 1, 2 e 3) e permaneceram alojados em baias coletivas. Todos foram vermifugados ${ }^{1}$ e submetidos a imunoprofilaxia com duas doses de vacina. ${ }^{2}$

Sobre uma área de osteotomia transversal completa, após o último pré-molar, os animais do grupo 1 receberam placas ortopédicas de aço inoxidável ${ }^{3}$ e os animais do grupo 2 receberam placas ortopédicas de PVC. Já os animais do grupo 3 receberam uma placa de cada tipo, respectivamente sobre cada corpo mandibular íntegro. As placas plás-

\footnotetext{
${ }^{1}$ Drontal plus. Bayer. SP.

2 Vacina Sêxtupla. Lab. Solvay Saúde Animal

${ }^{3}$ Aço Inox. Ortovet. SP.
}

ticas foram confeccionadas segundo Almeida e Rezende (1990) a partir de PVC oriundo de conexões, ${ }^{4}$ com espessura de $2 \mathrm{~mm}$ e tinham formato e tamanho semelhante aos das placas de aço. Os parafusos utilizados foram sempre de aço inoxidável. ${ }^{5}$

Após a confecção, as placas foram lavadas com água, detergente neutro e escova e posteriormente enxaguadas. Então, ficaram submersas numa mistura de água destilada, álcool etílico e azeite de oliva ${ }^{6}$ por um período de 12 horas, quando foram lavadas novamente e secas. As placas foram submetidas a esterilização química ${ }^{7}$ por um período de 10 horas, antes do procedimento cirúrgico.

Todos os cães receberam $3 \mathrm{mg}$ por $\mathrm{kg}$ de ceftiofur sódico, ${ }^{8}$ 12 horas antes da cirurgia. Em todos os grupos, a exposição do corpo da mandíbula foi realizada conforme descrito por Piermattei (1993). O periósteo foi incisado e em seguida afastado com auxílio de uma rugina e nos grupos 1 e 2 , uma osteotomia completa foi realizada entre o último dente pré-molar e primeiro molar, com auxílio de serra manual. As placas foram colocadas lateralmente no corpo da mandíbula, próximas à borda ventral, e fixadas primeiramente no fragmento caudal. Os orifícios ósseos foram perfurados com furadeira manual e durante o procedimento 0 local foi irrigado com solução fisiológica.

Os parafusos utilizados possuíam comprimento suficiente para se fixarem na cortical lingual do corpo da mandíbula e dois parafusos foram colocados a cada lado da linha de osteotomia, preenchendo os orifícios da placa (Figura 2), sem afetar as raízes dentárias.

No grupo 3, após exposição dos dois corpos mandibulares, uma placa de aço inoxidável foi colocada no lado direito e uma de PVC no lado esquerdo. Após a colocação das placas, o periósteo e o tecido subcutâneo foram aproximados individualmente com fio absorvível $3-0,{ }^{9}$ em sutura contínua, procedendo-se, em seguida, à síntese da pele, com fio inabsorvivel 3-0, ${ }^{10}$ em sutura de Wolff.

Uma incisão de pele de cerca de $2 \mathrm{~cm}$ na região dorsal esquerda, próximo à apófise transversa das vértebras lombares, foi realizada nos animais do grupo 2 , onde foram implantados fragmentos de PVC de $2 \times 2 \mathrm{~cm}$.

Os animais foram reconduzidos às baias em que estavam adaptados e receberam ração comercial, ${ }^{11}$ umedecida com água, duas vezes ao dia, por 20 dias e in natura pelo resto do experimento.

\footnotetext{
${ }^{4}$ Tubo de conexão, uso térmico. Marca Tigre. SP.

${ }^{5}$ Aço Inox. Ortovet. SP.

${ }^{6}$ Azeite de Oliva Galo. Victor Guedes Ind. e Com. Ltda.

${ }^{7}$ Germekil Instrumental. Darrow.

${ }^{8}$ Excenel. Lab. Rhodia.

${ }^{9}$ Catgut cromado 3-0. Brasmédica. S.A.

${ }^{10}$ Náilon cirúrgico 3-0. Farma Brasileira.

1 Ração Canina. Purina.
} 
Todos os animais foram sacrificados na 18a semana de pósoperatório, sendo o tecido ao redor das placas e aço e PVC e dos fragmentos de PVC implantados na região dorsal, submetidos a avaliação macroscópica, atentando para sinais de reação tecidual e presença de fístulas. Em seguida foi coletado e processado e os cortes histológicos foram corados pela Hematoxilinà e Eosina e pelo Tricrômio de Gomori. Na análise histológica foram avaliadas a presença e a intensidade da resposta inflamatória. A intensidade desta resposta foi classificada em leve, moderada e severa, de acordo com a neovascularização, edema e infiltrado celular.

\section{Resultados}

Ao exame macroscópico observou-se a partir de 90 dias do pós operatório fístula na pele ou na cavidade oral, na região do implante, em dois animais do grupo 1 , em três animais do grupo 2 , e em três animais do grupo 3 , sendo que neste último grupo havia uma fístula na região da placa de aço e duas na placa de PVC.

O tecido mole sobre os dois tipos de placa formou uma estrutura semelhante a uma cápsula de tecido conjuntivo fibroso, apresentando-se fina e lisa em alguns casos e em outros mostrava-se edemaciada e com secreção serosa na superfície em contato direto com a placa.

Microscopicamente, observou-se sobre os dois tipos de placa um tecido de granulação, ao qual estava sobreposto uma cápsula de fibras colágenas e, na periferia, tecido conjuntivo do subcutâneo. Naqueles animais onde a reação inflamatória ainda estava presente, o tecido de granulação aparecia como uma camada espessa com neovascularização, edema e células inflamatórias, polimorfonucleares (PMN) e mononucleares (MN). Nos demais animais, onde a reação inflamatória já havia cessado, observou-se apenas uma fina camada de células fibroblásticas sob a cápsula fibrosa (Figura 1).

A resposta inflamatória estava presente em $50 \%$ dos animais do grupo 1 e foi menos intensa (Figuras 2 e 3 ), enquanto que no grupo 2 estava presente em $80 \%$ dos animais (Figuras 2 e 3). Já no grupo 3 , a resposta inflamatória foi menos intensa, estando presente em $40 \%$ dos que receberam placa de aço e em $60 \%$ dos que receberam as confeccionadas de PVC (Figuras 2 e 3).

Figura 1: A) Reação tecidual sobre a placa de PVC. Presença de tecido de granulação $(\mathrm{g})$ : neovascularização (seta espessa), infiltrado celular (seta fina). Cápsula fibrosa (f) e tecido conjuntivo subcutâneo (s). B) Reação tecidual sobre a placa de PVC após término da reação inflamatória. Camada celular (seta), cápsula fibrosa ( $f$ ), tecido conjuntivo subcutâneo (s). $H \& E .32 X$.
Com relação ao infiltrado inflamatório, os animais que receberam placas de PVC apresentaram predomínio de infiltrado linfo-plasmocitário, difuso ou perivascular, com acentuada quantidade de plasmócitos (Figura 4), às vezes também no conjuntivo subcutâneo. Em 75 e $66 \%$ dos animais que receberam placas de PVC (grupos 2 e 3 respectivamente), onde persistia a resposta inflamatória, o

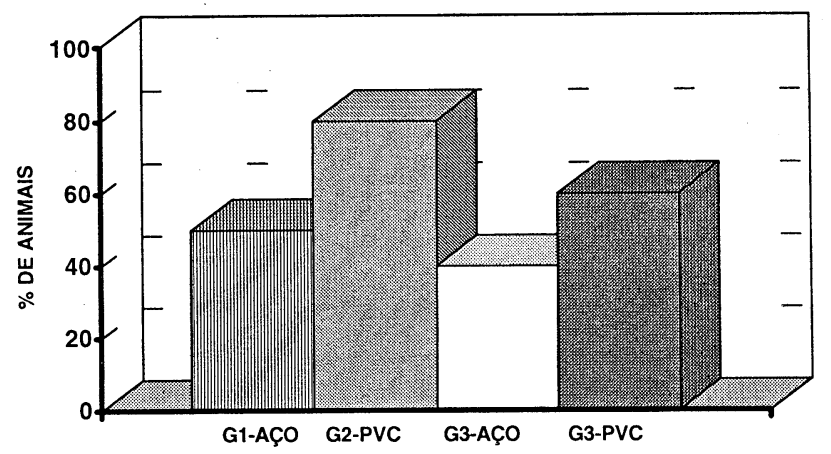

Figura 2: Percentagem de animais dos diferentes grupos (G1,G2 e G3) com presença de reação inflamatória, na $18^{a}$ semana de pósoperatório.

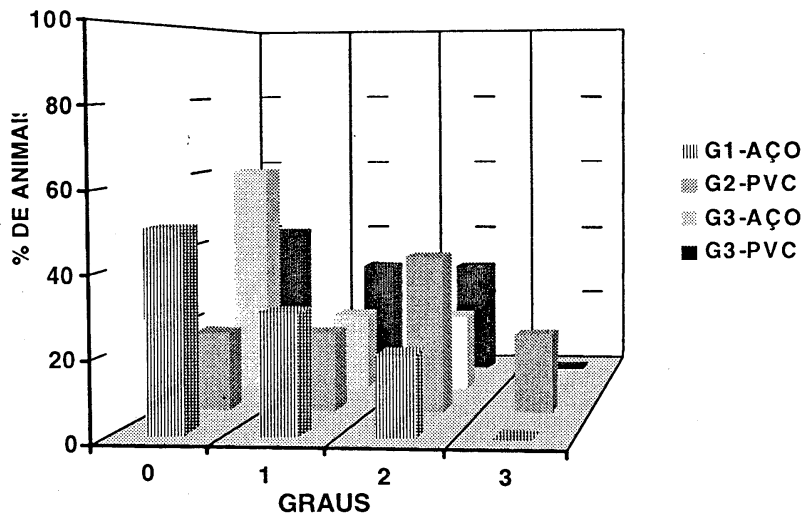

Figura 3: Distribuição percentual dos animais conforme o grau de reação inflamatória, dentro de cada grupo
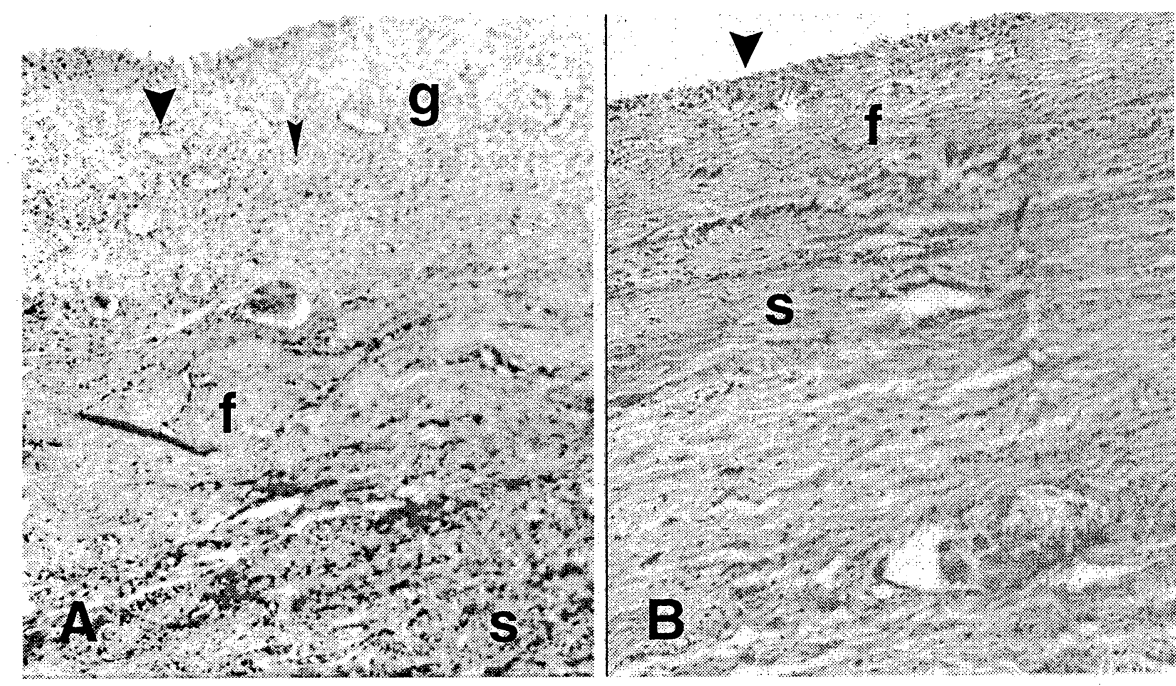
infiltrado linfo-plasmocitário perivascular organizava-se de forma semelhante a microgranulomas e, neste caso, as células endoteliais apareciam tumefeitas, havendo também polimorfonucleares (Figura 5). Com relação ao fragmento de PVC implantado no subcutâneo, $60 \%$ dos animais mostraram reação inflamatória semeIhante à observada sobre a placa, porém em menor intensidade.

Já nos animais que receberam placas de aço (grupos 1 e 3 ), predominavam células mononucleares no infiltrado inflamatório (Figura 4), observando-se
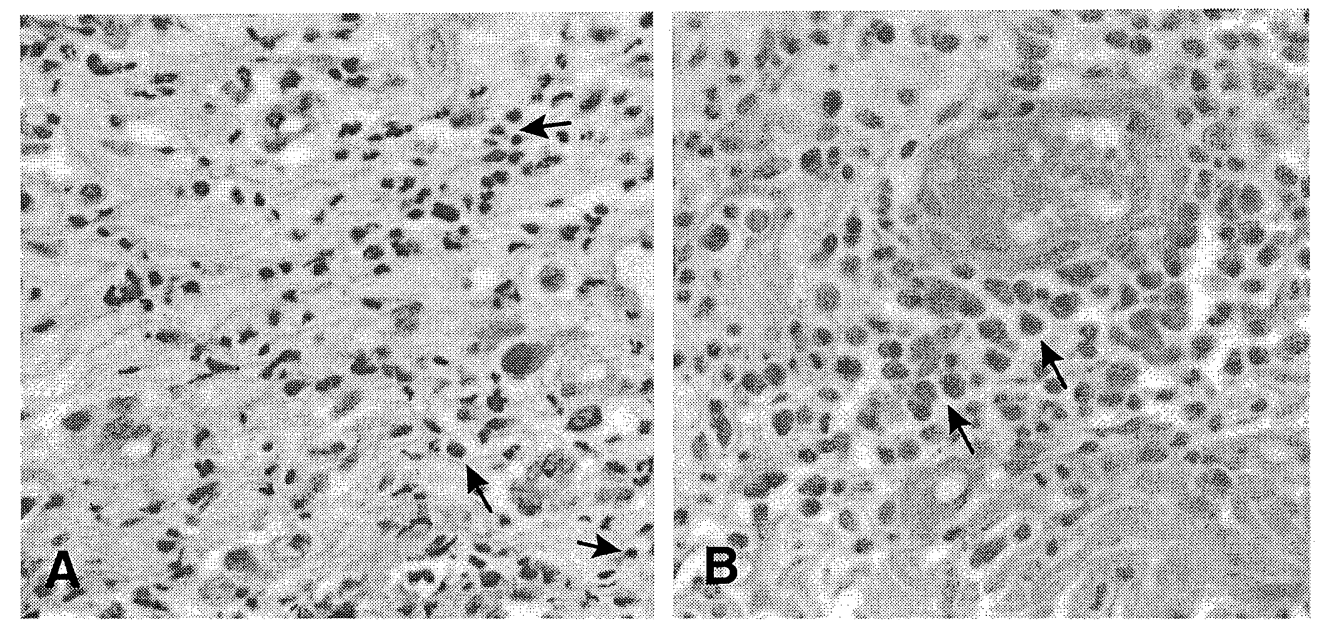

Figura 4 - A): Predomínio de infiltrado inflamatório mononuclear no tecido de granulação sobre a placa de aço (setas). H \& E. 128X. B) Infiltrado linfo-plasmocitário perivascular, com acentuada quantidade de plasmócitos (setas) no tecido de granulação sobre a placa de PVC. H \& E. 128X.

também presença de polimorfonucleares, porém em maior quantidade, naqueles que apresentavam fístula, à semelhança do que foi observado nos animais que receberam placa de $\mathrm{PVC}$.

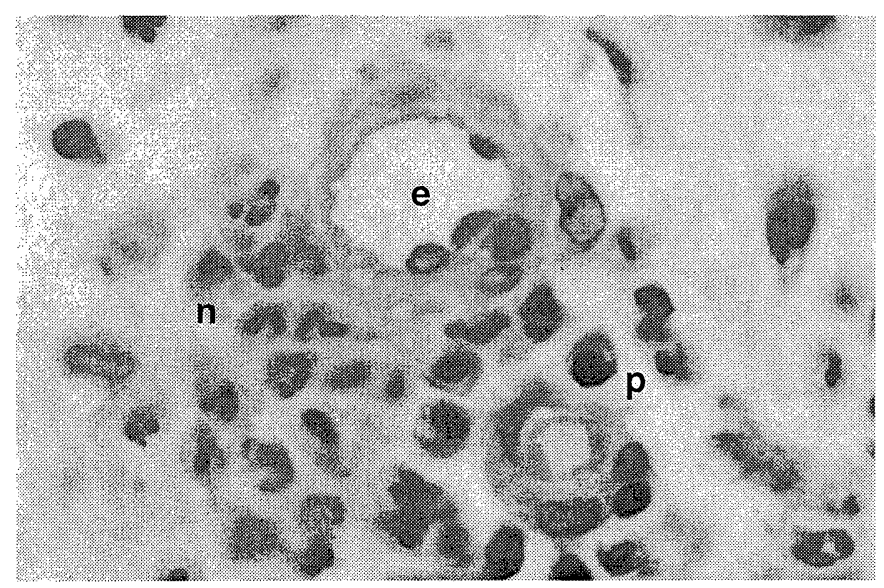

Figura 5: Células endoteliais tumefeitas (e). Infiltrado linfo-plasmocitário (p) e neutrófilos perivascular $(n)$ no tecido de granulação sobre a placa de PVC. H\& E. 320X.

\section{Discussão}

As placas de PVC foram confeccionadas com forma e tamanho semelhantes às de aço, e introduzidas mediante a mesma técnica cirúrgica (Marchant et al.,1984a; Morehead, Holt, 1994). Desta forma, pode-se inferir que a reação inflamatória observada em $80 \%$ e $60 \%$ dos animais que receberam placas de PVC (grupos 2 e 3 respectivamente) em comparação com $50 \%$ e $40 \%$ dos animais que receberam placas de aço (grupos 1 e 3, respectivamente), esteve diretamente relacionada a algum componente do plástico, pois, segundo Rubin et al. (1971), este tipo de reação aoredor de implantes é influenciado por sua composição química. Além disto, alguns aditivos presentes no plástico são tóxicos e podem migrar para o meio que o rodeia (Wu et al.,1989).

Hench e Ethridge (1982) consideraram que os componentes dos polímeros são mais tóxicos que a maioria dos íons liberados por implantes metálicos, e que eles são liberados de forma contínua, levando a persistência da resposta inflamatória com conseqüente retardamento na reparação tecidual. Assim, com base no que foi exposto, acredita-se que a toxicidade foi responsável pela diferença na persistência do processo inflamatório e também pela intensidade da resposta observadas ao redor dos dois tipos de placas.

Rodriguez Alvarez (1990) sugeriu inocuidade deste material aos 30 dias pós-operatórios. Entretanto, no presente experimento, constatou-se reação inflamatória nos animais que receberam placa de PVC, à semelhança do observado por Tudury (1996) aos 45 dias após a cirurgia. Esta diferença de resultados pode estar relacionada não somente ao tempo de observação, como ao tipo de PVC utilizado, já que, embora sejam da mesma marca, pode ter havido alterações em sua composição (Tudury, 1996), confirmando a idéia de que alguns componentes em sua constituição podem ter sido liberados.

Deve ser ressaltado ainda que o PVC utilizado neste trabaIho, oriundo de conexões plásticas, não foi elaborado para uso médico, portanto, ele agrega uma série de subprodutos da indústria plástica que podem induzir a reações indesejáveis nos tecidos corporais. Além disso, sua composição varia muito, por ser constituído de subprodutos reciclados. Este fato está de acordo com a afirmação de Counsell et al. (1985) de que aditivos e materiais estranhos devem estar ausentes quando se utiliza polietileno em cirurgia reconstrutiva.

Já a intensidade diferente da resposta inflamatória às placas de PVC, observada entre os grupos 2 e 3 , seguramente teve influência a osteotomia realizada no grupo 2 , pois 
o trauma cirúrgico maior e a própria fratura, desencadeando uma resposta inflamatória e também alterando o meio ao redor do implante (Mariolani, 1991), podem ser responsabilizados pelo maior afluxo celular.

Além disto, é importante lembrar que as alterações locais podem ter influenciado a migração para o meio de estabilizantes e plastificantes, componentes do PVC que de acordo com Gebelein (1985), exacerbam o processo inflamatório e agem como um estímulo para a sua persistência. Assim, justifica-se porque os fragmentos de PVC introduzidos no tecido subcutâneo dos animais do grupo 2 , induziram uma reação inflamatória mais discreta do que a reação ao redor da placa.

A reação inflamatória crônica com predomínio de infiltrado linfo-plasmocitário, induzida pelas placas de PVC (grupos 2 e 3), é sugestiva de reação imunomediada, já que, segundo Pereira e Bogliolo (1993), as inflamações crônicas com este tipo de infiltrado são indicativas de imunidade do tipo humoral. Ainda, o possível caráter imunológico da reação ao PVC, poderia ser explicado pelo fato de que, segundo Ward et al. (1976), produtos metabólicos do PVC podem ser incorporados a proteínas, tornando-as antigênicas, ou mesmo ser incluídos a resíduos de cloro em uma molécula protéica, assumindo, assim, um efeito haptênico e estimulando a síntese de anticorpos.

Reação inflamatória crônica granulomatosa, com infiltrado celular semelhante ao constatado neste experimento, foi observada por Tudury (1996), que também sugeriu um mecanismo imunológico. Porém, o granuloma típico com células gigantes e células epitelióides, reportado por este autor, não foi observado nesta pesquisa, possivelmente devido a uma maior toxicidade do PVC utilizado, pois, segundo Marchant et al. (1984a), implantes citotóxicos podem lesar macrófagos que estejam em processo de fusão, inibindo a formação de células gigantes.

As alterações vasculares observadas nos grupos que receberam placas de PVC, tais como infiltrado inflamatónio perivascular, e tumefação das células endoteliais também foram citadas por Magnavita et al. (1986) e Tudury (1996), sendo sugestivas de vasculites, possivelmente tóxicas ou imunomediadas, pois, segundo Ward et al. (1976), o PVC pode acarretar vasculopatias por deposição de imunocomplexos.

A reação inflamatória ao redor da placa de aço em $50 \%$ dos animais possuía infiltrado com predomínio de células mononucleares caracterizando, assim, uma inflamação crônica. A presença do material determinou irritação física persistente do tecido, concordando com as afirmações de Marchant et al. (1984b). Este fato é reforçado pela constatação de polimorfonucleares no exsudato, havendo desta forma resposta inflamatória aguda coexistindo com um processo inflamatório crônico. Ainda, íons podem ter sido liberados e a sua toxicidade pode ser um fator importante na reação dos tecidos (Laing et al.,1967), desencadeando reações inflamatórias com intensidade diferente, conforme observado por Uhthoff et al. (1981).

A diferente intensidade da resposta inflamatória observada nos animais que receberam placas de aço (grupos 1 e 3 ) sugere, mais uma vez, a influência da osteotomia realizada nos animais do grupo1.

Segundo Morehead e Holt (1994), as reações teciduais a implantes variam em intensidade, desde rejeição com extrusão, para encapsulamento fibroso e, finalmente, para integração. Então, as fístulas presentes na região do implante, nos animais dos três grupos, sugere um processo de rejeição, pois nestes animais também havia intenso infiltrado de polimorfonucleares, o que poderia indicar agudização da reação, intensificando-a, apesar de não ter sido observado afrouxamento dos parafusos, presente no processo de rejeição, conforme indicado por Gebelein (1985) e Smith (1985). Entretanto, o fato de ter sido observado somente em oito animais do experimento (grupos 1, 2 e 3), pode estar relacionado a resposta individual ao material (Smith,1985).

A formação de cápsula fibrosa naqueles animais onde 0 processo inflamatório já havia cessado, indica que o tecido de granulação foi substituído, gradualmente pelo acúmulo de matriz colágena, e também que a sua organização precedeu a formação da mesma (Davidson,1992).

\section{Conclusão}

Placas ortopédicas confeccionadas com PVC fixadas ao corpo mandibular de cães e fragmentos do material inseridos no dorso dos animais, determinaram alterações histológicas no tecido circundante, após 18 semanas de implantação, qualitativamente diferente daquelas observadas sobre placas de aço inoxidável, afetando maior número de animais e em maior intensidade, sendo sugestivas de toxicidade e antigenicidade do material.

\section{Abstract}

By histopatthologic study the conjunctive tissue reaction around plates made from polyvinyl chloride was evaluated. Thirty adult dogs, with average weight of $13 \mathrm{~kg}$, were placed in 3 groups of $10 \mathrm{dogs}$. In the groups 1 and 2 , a transverse osteotomy line was performed in the right mandibular body, cranial to the first molar tooth and the fracture was fixed with bone plates manufactured by steel and PVC, respectively. In the group 3 the right and left undamaged mandibular bodies received each one in differents plates, steel and PVC. In the week 18 a chronic inflamatory reaction was observed around the newly tissue formation wich was promoted by the PVC plates. This reaction pattern was different, in quality from the steel's plate, affecting with a stronger intensity a larger number of animals, suggesting toxicity and antigenicity.

Keywords: polyvinyl chloride; PVC; bone plates. 


\section{Referências bibliográficas}

ALMEIDA, A.E.R., REZENDE, C.M.F. Confecção de placas ortopédicas de cloreto de polivinila para redução de fraturas de ossos longos do cão. In: CONGRESSO MINEIRO DE MEDICINA VETERINÁRIA, 4. 1990, Belo Horizonte. Anais... Belo Horizonte: UFMG - Escola de Veterinária, 1990. p. 82. Resumo.

COOK, W.A., GIEVER, P.M., DINMAN, B.D., MAGNUSON, H. J., $\mathrm{MICH}$, A.A. Occupational Acroosteolysis. II. An industrial hygiene study. Arch. Environ. Health, v. 22, p. 74-82, 1971.

COUNSELL, M., McKEOWN, D., PENNOCK, P. Mandibular osteotomy repair using high density polyethylene plates. $J$. Am. Anim. Hosp. Assoc., v. 21, p. 685-690, 1985.

DAVIDSON, J.M. Wound repair. In: GALLIN, J.I., GOLDESTEIN, I.M., SNYDERMAN, R. Inflammation. Basic principles and clinical correlates. New York: Raven Press, 1992. p. 809-820.

GEBELEIN, C.G. Medical applications of polymers. In: TESS, R.W., POEHLEIN, G.W. Applied polymer science. Washington: American Chemical Society, 1985. p. 535-556.

HENCH, L.L.; ETHRIDGE, E.C. Biomaterials: An interfacial approach. New York: Academic Press, 1982. 386 p.

LAING, P.G., FERGUSON JÚNIOR, A.B.., HODGE, E.S. Tissue reaction in rabbit muscle exposed to metallic implants. $J$. Biomed. Mat. Res., v. 1, p. 135-149, 1967.

MAGNAVITA, N., BERGAMASCHI, A., GARCOVICH, A., GIULIANO, G. Vasculitic purpura in vinyl chloride disease: $A$ case report. Angiology, v. 37, p. 382-388, 1986.

MARCHANT, R.E., ANDERSON, J.M. In vivo biocompatibility studies. VII. Inflamatory response to polyethylene and to a cytotoxic polyvinylchloride. J. Biom. Mat. Res., v. 20, p. 37-50, 1986.

MARCHANT, R.E., MILLER, K.M., ANDERSON, J.M. In vivo biocompatibility studies. V. In vivo leuckocyte interactions with biomer. J. Biom. Mat. Res., v.18, p. 1169-1190, 1984a.

MARCHANT, R.E., MILLER, K.M., HILTNER, A., ANDERSON, J.M. Selected aspects of cell and molecular biology of in vivo biocompatibility. In: SHALABY, W. SHALABY. Polymers as biomaterials. New york: Plenum, 1984b. p. 209-223.

MARIOLANI, J.R.L. Metodologia para avaliação da interface biomaterial/tecido ósseo: estudo teórico e experimental. Campinas: UNICAMP, 1991. 105 p. Dissertação (Mestrado em Engenharia Mecânica) - Universidade de Campinas, 1991.
MILLER, K.M., ANDERSON, J.M. In vitro and in vivo interactions of cells with biomaterials. Biomaterials, v. 9, p. 5-13, 1988.

MOREHEAD, J.M., HOLT, G.R. Soft-tissue response to syntetic biomaterials. Otolaryng. Clin. North Am., v. 27, n. 1, p. 195201, 1994.

PEREIRA, F.E.L., BOGLIOLO, L. Inflamações. In: BRASILEIRO FILHO, G., PEREIRA, F.E.L., PITTELLA, J. E.H., BAMBIRRA, E.A., BARBOSA, A.J.A. Patologia geral. Rio de Janeiro: Guanabara Koogan, 1993. p. 111-143.

PIERMATTEI, D.L. The head. In: An atlas of surgical approaches to the bones and joints of the dog and cat. $3^{\text {rd }}$ ed. Philadelphia : W. B. Saunders, 1993. p. 31-37.

RODRIGUEZ ALVAREZ, L.M.R. Emprego de placas de cloreto de polivinila na fixação de fraturas no terço distal do rádio e ulna do cão novo (canis familiares). Estudo experimental. 1990. 44p. Dissertação (Mestrado em Medicina Veterinária) - Escola de Veterinária da Universidade Federal de Minas Gerais, 1990.

RUBIN, R. L., BROMBERG, B.E., WALDEN, R.H. Long term human reactions to synthetic plastic. Surgery Ginecology. \& Obstetric, v. 132, p. 603-608, 1971.

SMITH, G.K. Orthopedic biomaterials. In: NEWTON, C. D., NUNAMAKER, D.M. Textbook of small animal orthopedics. Philadelphia : J. B. Lippincott, 1985. p. 231-241.

TUDURY, E.A. Imobilização interna da coluna vertebral lombar com placas de cloreto de polivinila, em cães. Estudo Experimental. 1996. 85 p. Tese (Doutorado em Medicina Veterinária) - Escola de Veterinária da Universidade Federal de Minas Gerais, 1996.

UHTHOFF, H.K., BARDOS, D.I., LISKOVA-KIAR, M. The advantages of titanium alloy over stainless steel plates for the internal fixation of fractures. An experimental study in dogs. J. Bone Joint Surg., v. 63-B, n. 3, p. 427-434, 1981.

WARD, A.M., UDNOON, S., WATKINS, J., WALTER, A.E., DARKE, C.S. Immunological mechanisms in the pathogenesis of vinyl chloride disease. Br. Med. J., v. 1, p. 936-938, 1976.

WU, W., ROBERTS, R.S., CHUNG, Y.C., ERNST, W.R., HAVLICEK, S.C. The extraction of organotin compounds from polyvinyl chloride pipe. Arch. Environ. Contam. Toxicol., v. 18, p. $839-843,1989$. 